\title{
Making Agriculture More Intelligent: Progress of Agricultural Robots
}

\author{
Lihua Jiang ${ }^{*}$ and Yantao Zhang² \\ ${ }^{1}$ Suzhou Polytechnic Institute of Agriculture, China \\ ${ }^{2}$ School of Construction Machinery, Chang'an University, Xi'an, China
}

Submission: November 09, 2018; Published: November 29, 2018

*Corresponding author: Lihua Jiang, Suzhou Polytechnic Institute of Agriculture, China

\section{Abstract}

In this paper, we present a mini review to investigate the development progress of agricultural robots from different perspectives including classification, functionality, and characteristics. The current technical situations and features of grafting robot, picking robot, weeding robot, spraying robot, etc. are introduced with their corresponding application contexts. It is analyzed and concluded that high cost and intellectualization are two major factors that may challenge the popularity of agricultural robots. The development trends of agricultural robots are discussed as well.

Keywords: Agricultural Robot; Intelligent Agriculture; Grafting robot; Picking robot; Weeding robot; Spraying robot.

\section{Introduction}

Robotic technology has been wide used in different areas, such as home service, health care, advanced manufacturing, and agricultural industry [1-4]. Agricultural robot is a kind of automation equipment, which takes agricultural products as the operation objects with environmental perception and automated working function [5]. It is the outcome of the rapid development of information technology. The use of agricultural robots can effectively improve production efficiency, reduce the labor burden of farmers and solve the problem of labor shortage. At present, great progress have been made in the field of agricultural robot. Robots adapting to different needs have emerged one after another, such as pesticide spraying robots, grafting robots, picking robots, harvesting robots [6-9]. The extensive use of agricultural robots is promoting the modern agricultural production to be increasingly intensive and large-scaled.

\section{Classification and Features of Agricultural Robots}

\section{Classification of agricultural robots}

With the advent of the era of agricultural mechanization, many countries have invested greatly in the research and development of agricultural robots. Various types of robots have appeared frequently $[10,11]$. According to the different working objects, agricultural robots can be divided into farm robot, fruit and vegetable robot, animal husbandry robot and forest robot. The specific classification is shown in Table 1 [12].

Table 1: Classification of agricultural robots.

\begin{tabular}{|c|c|c|}
\hline Type & Name & Function \\
\hline \multirow[b]{2}{*}{ Farm Robots } & Spraying robot & $\begin{array}{l}\text { Depends on the pest identification and control system. Pesticides can be sprayed according to } \\
\text { the type and quantity of pests. }\end{array}$ \\
\hline & Weeding robot & $\begin{array}{c}\text { Based on image processing system and positioning system, weed identification and positioning } \\
\text { can be realized. Herbicide selection and spraying can be carried out according to the number } \\
\text { and species of weeds. }\end{array}$ \\
\hline \multirow{3}{*}{ Fruit and vegetable Robots } & Grafting robot & $\begin{array}{l}\text { Used for grafting vegetables and fruits and working together with the millimeter diameter } \\
\text { embryo. }\end{array}$ \\
\hline & Picking robot & Finding and identifying mature fruits through visual sensors \\
\hline & Sorting robot & Can identify the size of fruit and classify the fruit accordingly. \\
\hline
\end{tabular}




\section{Robotics \& Automation Engineering Journal}

\begin{tabular}{|c|c|c|}
\hline \multirow{2}{*}{ Animal husbandry Robots } & Milk robot & $\begin{array}{c}\text { Sensors are used to detect whether cows are suitable for milking, and then to detect nipple } \\
\text { position. It can manage the milk quality and quantity in an integrated way [12]. }\end{array}$ \\
\cline { 2 - 3 } & lumbering robot & $\begin{array}{c}\text { Driven by hydraulic system, the manipulator of robot can clean up on the different slopes and } \\
\text { terrain. }\end{array}$ \\
\hline
\end{tabular}

\section{Features of agricultural robots}

Compared with industrial robots, agricultural robots have the following features:

\section{A. Complexity and hard predictability of the operating} environment

Crop shape and size always change with time. Crop growth environment is complex and changeable, which brings a severe challenge to the operation ability of robots. This requires agricultural robots to have strong adaptability and achieve high intelligence in visual reasoning and judgment [13-15].

\section{B. Seasonality of operating}

Due to the limitation of technical level, most robots only have a single function and work in a certain part of agricultural production, which determines that robotic operation has seasonal characteristics.

\section{Particularity of users and prices}

On the one hand, agricultural robots are mostly used by farmers with low knowledge level, which requires that agricultural robots must be simple and easy to operate. On the other hand, the overall profit of agricultural products is not high, which determines that the price of agricultural robots cannot be too high [16-18].

\section{Research Status of Agricultural Robots}

\section{Grafting robot}

The research of automatic grafting equipment is mainly in Japan, South Korea and China. Japan is the first country to develop grafting robots, and then South Korea began to do this research. In 1986, Japan Society for research and development introduced three grafting prototypes, and then Japanese Institute of Mechanization invented a fully automatic vegetable grafting machine. Among them, the most representative type is Jing guan GR800, which was introduced -to the market in October 1993. GR800 uses artificial rootstocks and joints, and its success rate of grafting is about 90\% [19-21]. TGR Institute of Japan introduced the grafting machine for melon grafting in 1995.

South Korea began to study the grafting robots in the 1990s. The needle-type automatic grafting machine introduced by South Korean Ideal System Company is their typical product. The machine uses anti-rotation pentagonal ceramic needles to graft. The whole hole tray can provide seedlings. The grafting speed can reach 1200 plants/hour, as shown in Figure 1. Chinese research on grafting robots started relatively late. China Agricultural University is one of the earliest universities in China to study agricultural robots [22-25]. The automatic grafting robot invented by them has been tested in production. The robot solves the problems of tenderness, vulnerability and inconsistent growth of seedlings, and can be used in cucumbers, watermelons, etc. The grafting robots is shown in Figure 2.

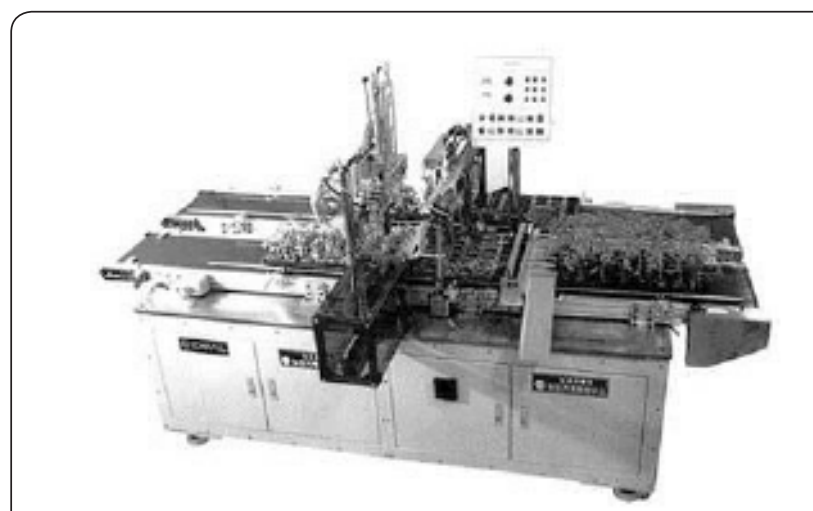

Figure 1: Needle-type automatic grafting machine designed by Ideal System Company in South Korea.

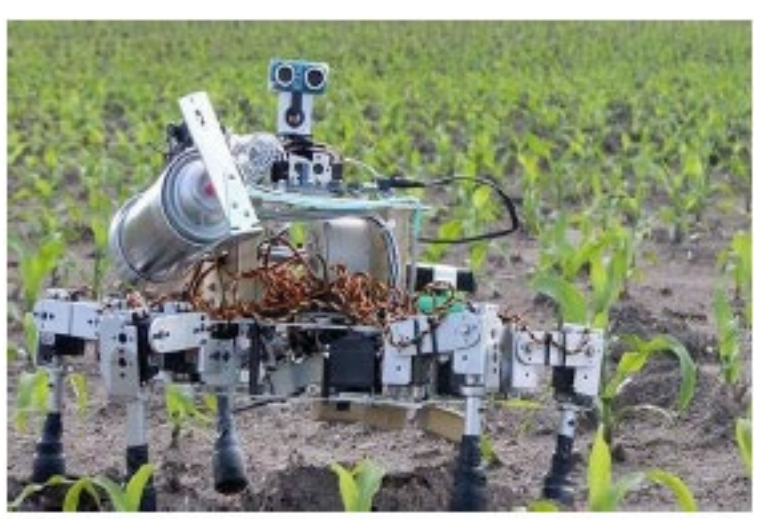

Figure 2: Grafting robot designed by Chinese Agricultural University.

\section{Picking robot}

For picking robots, Tomato picking robot was the first one studied. The picking robot developed by Knoto et al. in Japan was the most influential one at that time [26]. The robot mainly consists of three parts: manipulator, vision sensor and mobile mechanism. It separates fruit handle from fruit tree by rotation of wrist joint. In 2004, California Machinery Company launched an automatic Tomato Picking robot, which picked fruit and leaves into the sorting bin, and then selected the fruit through sorting equipment. The separated leaves were broken and sprinkled into the field as fertilizer.

The tomato picking robot developed by Japanese Panasonic Corp is shown in Figure 3. The small lens is used by the robot can shot more than 70 thousand pixels of color images. Firstly, the robot detects mature red tomatoes by image sensors, and then locates the shape and position accurately. When picking, the robot can only pull the vegetable pedicel without damaging the fruit. It 


\section{Robotics \& Automation Engineering Journal}

can work continuously at night without human supervision. China began to contact picking robots in the mid-1990s. For a period of time, universities and research institutes in China have been devoting themselves to the research and development of picking robots and has made some achievements. For example, Shenyang
Institute of Automation has invented a tomato picking robot. As shown in Figure 4, its manipulator is a four-fingered structure. The manipulator is equipped with a vacuum suction cup driven by an air pump, which can be used for fruit picking by the adsorption of the suction cup.

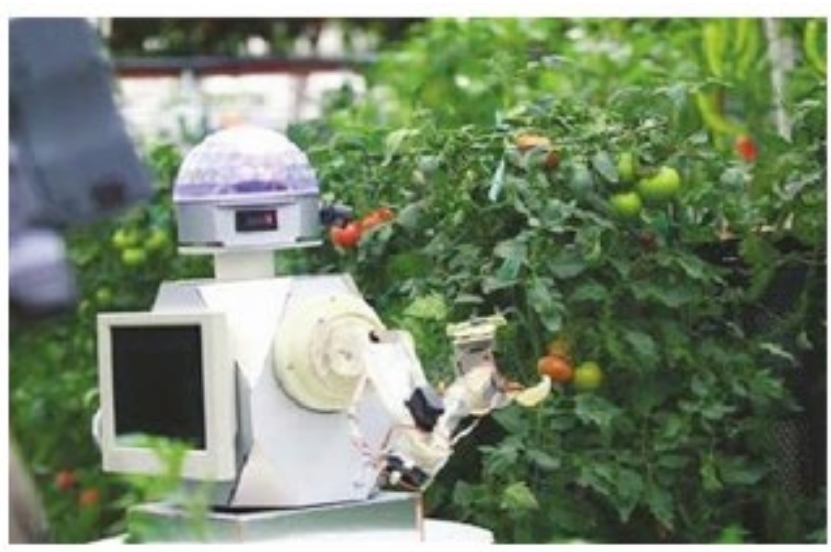

Figure 3: Tomato picking robot designed by Panasonic Company in Japan.

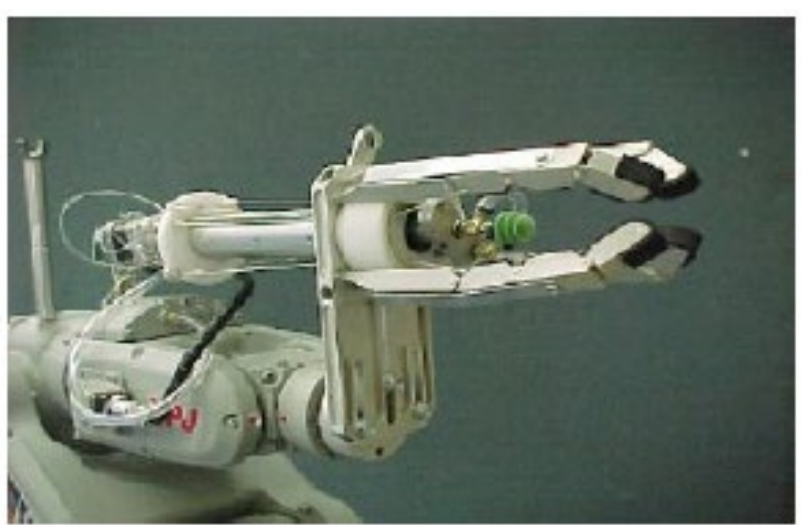

Figure 4: Tomato picking robot designed by Shenyang Institute of Automation in China.

\section{Weeding robot}

At present, weed removal in the field is a big problem that puzzles farmers. The general weeding methods are artificial weeding and pesticide spraying. These methods not only consume labor but will also cause soil pollution. Researchers at Wageningen University in the Netherlands have designed an automatic weeding robot, which uses a diesel engine as power source and can realize four-wheel steering. The robot uses D-GPS and machine vision to navigate [27]. It can collect the boundary information of farmland in real time and drive along the route of crops independently. The robot also uses advanced vision technology to identify weeds.

Researchers of the Helmstad University in Sweden have developed a weeding robot, which is controlled by a DC servo motor and uses the Ackerman steering on a car as a control mechanism [28]. The robot has two cameras, one of which is a white camera for identifying crop routes and guiding them. The robot travels along the crop and another color camera is used to identify the weeds. It is proved by experiments that the navigation accuracy of the robot can reach $\pm 2 \mathrm{~cm}$. as shown in Figure 5 . German scientists have developed a weeding robot named BoniRob [29]. As shown in Figure 6, the GPS positioning system of the robot can accurately record the position of weeds and control the accuracy within $2 \mathrm{~cm}$. BoniRob can remove 120 weeds in a minute, much faster than manual and medicines.

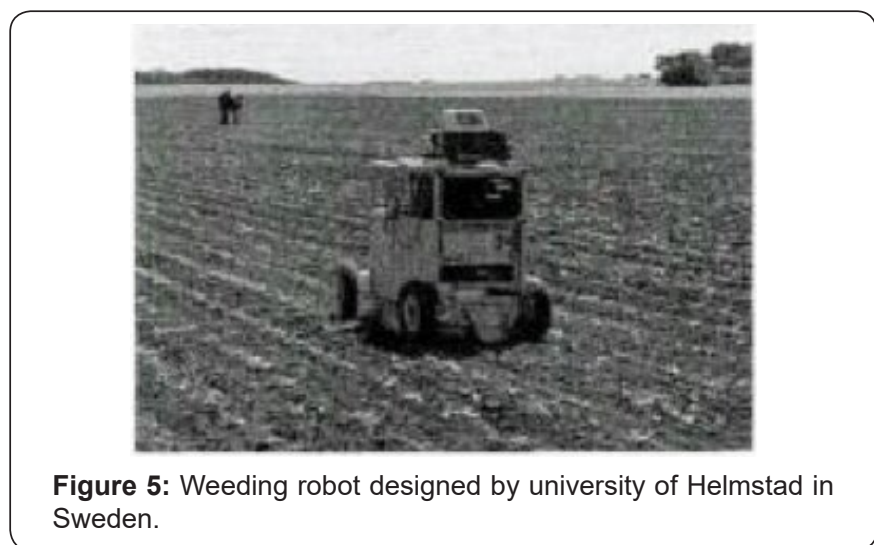




\section{Robotics \& Automation Engineering Journal}

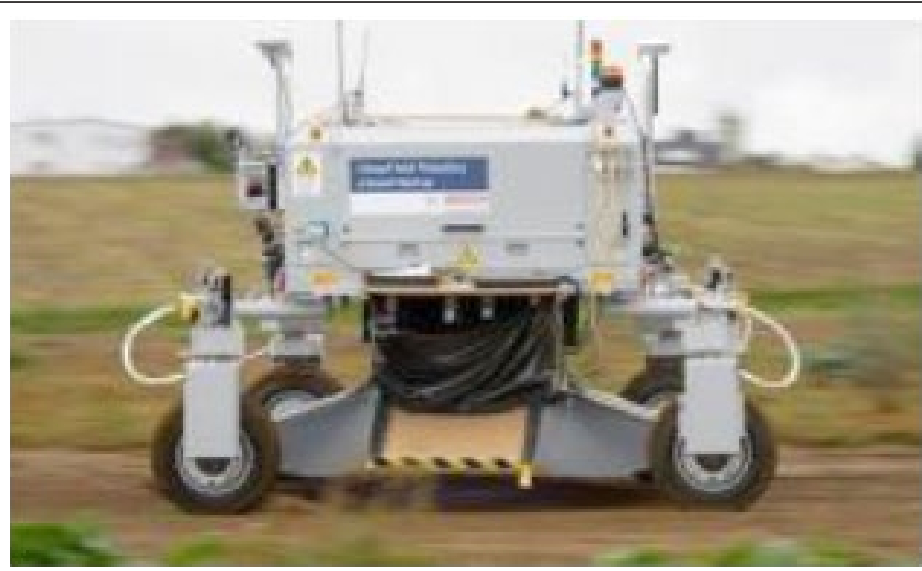

Figure 6: Weeding robot designed by BoniRob in German.

\section{Spraying robot}

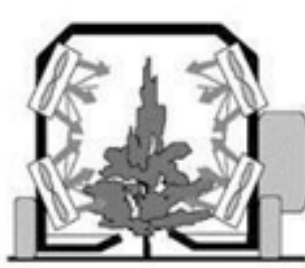

A

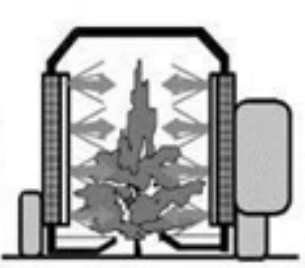

B

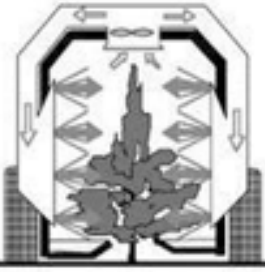

C

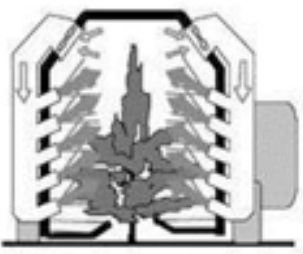

D

Figure 7: Tunnel type sprayer designed by Holland researchers.

Holland researchers have developed a tunnel type circular sprayer, as shown in Figure 7. The robot has a tunnel shaped cover. When spraying, the cover covers the crops to be sprayed, so that the whole spraying process is carried out in a relatively confined space. This reduces the influence of air flow on droplets. The cover also has a liquid recovery system avoiding the waste of liquid medicine. The robot is mainly used for pest control of crops with lower crowns.
In 1990, Yamamoto launched the first unmanned helicopter for pesticide spraying in the world. As shown in Figure 8, the agricultural unmanned aerial vehicle is efficient, safe and free from terrain restrictions. However, at present, spraying equipment in China are mostly manually-driven, and only a few can self-walk. A tractor sprayer has been developed by Chinese researchers, which combines tractor with sprayer, and realizes indiscriminate spraying, as shown in Figure 9.

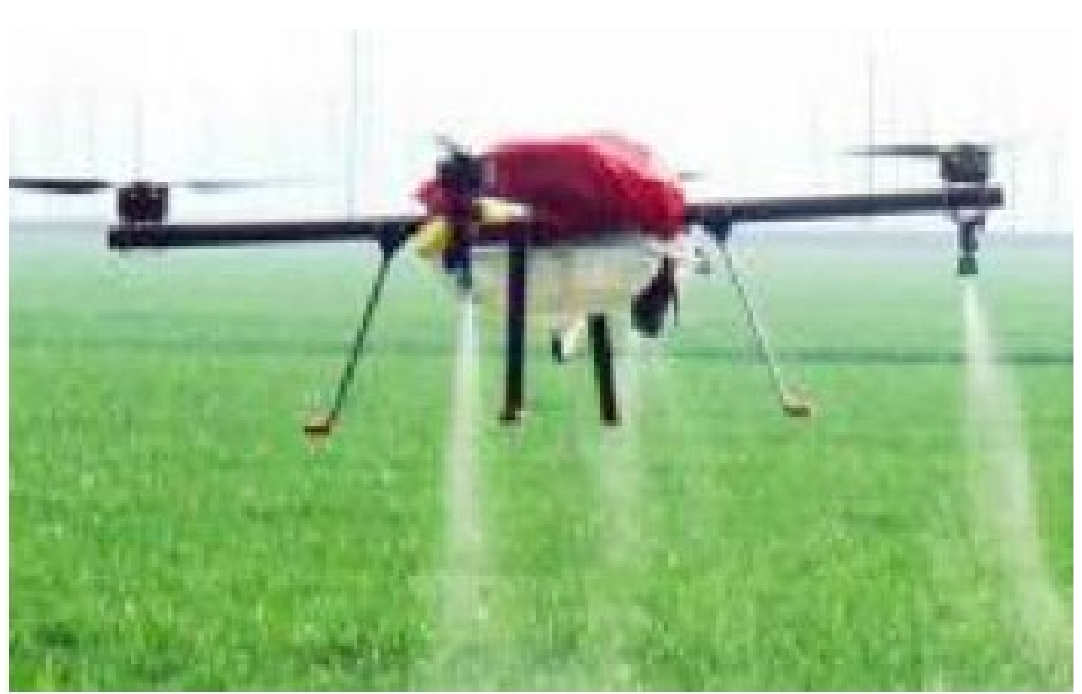

Figure 8: Spraying UAV designed by Yamamoto. 


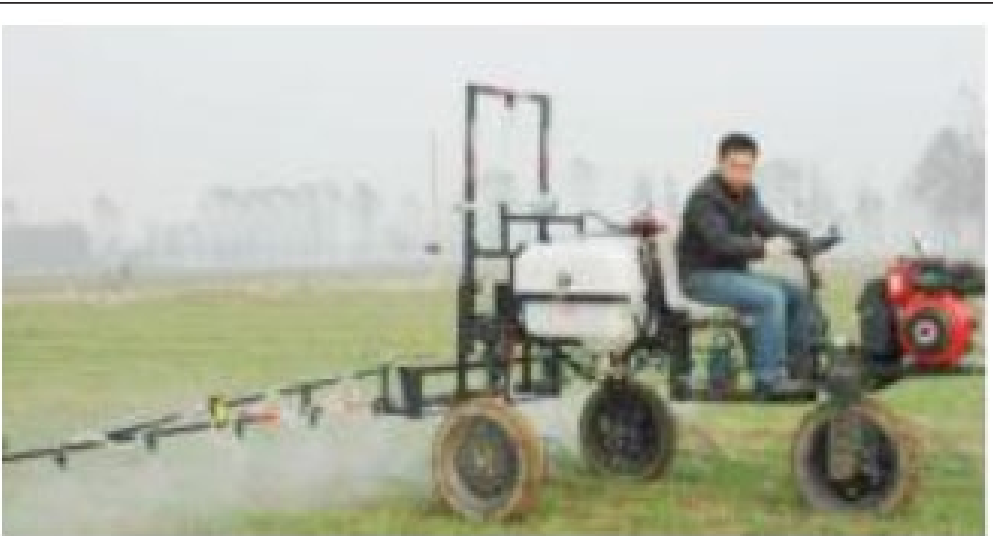

Figure 9: Sprinkler designed by China researchers.

\section{Other types of agricultural robots}

Since the beginning of the $21^{\text {st }}$ century, the research and development of agricultural robots in various countries have developed vigorously. Various agricultural robots adapting to different needs have emerged, such as the seedling-raising robot developed in Boston, USA. It consists of rolling tires, grippers and trays. Workers only need to set location parameters on the touch screen, and the robot can automatically move to the designated working place and effectively shorten the seedling period.
A fruit sorting robot has been developed in the U.K., as shown in Figure 10. The robot is equipped with an electronic image sensor. It can recognize not only the size and shape of the fruit, but also the color of the fruit, and judge the maturity of the fruit. The robot picks the fruit by the giant pincers connected to the vacuum tube to ensure that the fruit is intact. A grazing robot invented by an Australian inventor uses two-dimensional and threedimensional sensors, and the built-in global positioning system can automatically detect the movement speed of cattle and drive them away, as shown in Figure 11.

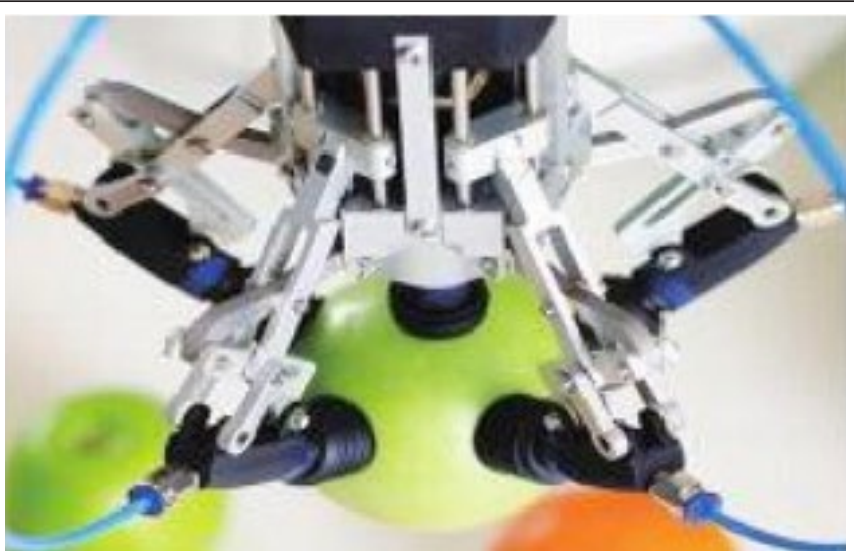

Figure 10: Sorting robot designed by Agricultural.

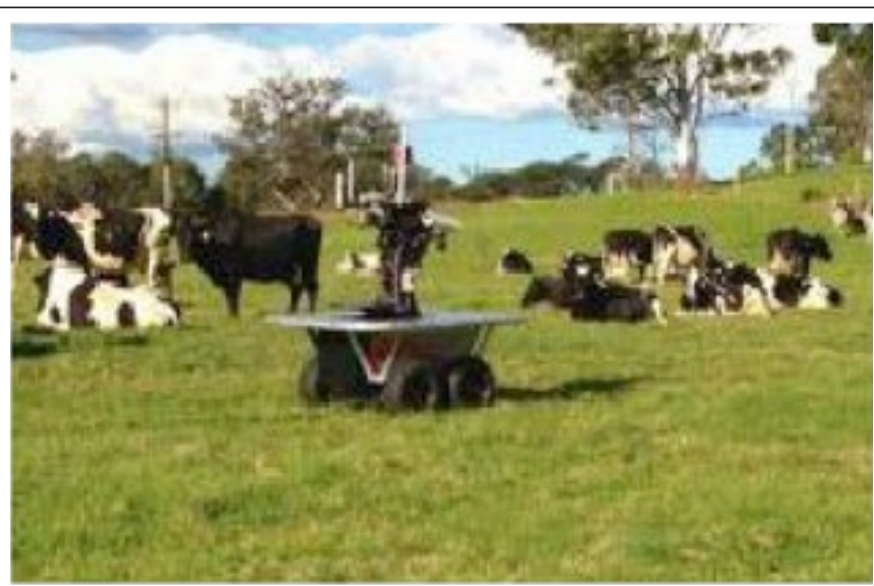

Figure 11: Grazing robot designed by Australia researchers Machinery Institute in British. 


\section{Development Trends and Technical Challenges of Agricultural Robots}

Although great achievements have been made in the development of agricultural robots so far, there is still a long way to go before the popularization of such robots. By taking the references of robot applications in other fields, some development trends of agricultural robots can be foreseen as follows:

A. Developing more advanced action planning approaches for agricultural robots to improve the agricultural task quality. In some cases, when the robot conducts an assigned agricultural task, it may be inevitable have some negative influences on other targets. For example, when a picking robot picks some apples from the three, it may produce some harmful actions on thin branches or leaves by its links or end-effector. Therefore, some advanced robot action planning algorithms based on cost functions can be developed to address such issues to improve the agricultural task quality [30].

B. With the increasing complexity of agricultural tasks, traditional agricultural robots cannot finish the tasks effectively and accurately. Therefore, humans need to be involved in such situations, which have similarly happened in manufacturing contexts [31]. Human farmer-agricultural robot collaboration will be a research topic on the way of agricultural robot development.

C. Making the agricultural robot more considerate will be a trend in its development. With the development of agricultural requirements, the agricultural robot will transfer from a machine to be a "human partner" in most of agricultural contexts [32]. Therefore, the intelligence of the agricultural robot such as understanding human intentions will be a large gap to be filled [33].

D. Developing easy-to-use programming approaches for agricultural robots. As we know, it is difficult for the farmer users to program robots with professional expertise when they want to update the robot to new agricultural tasks. Therefore, developing new approaches by integrating multi-modal human information such as natural language or wearable sensing to have farmers program agricultural robots intuitively and to make robot understand or predict human intentions effectively will also be a distinct trend for agricultural robots [34].

\section{The main challenges lie in the following two aspects [35]}

The cost is too high: In order to adapt to the complex working environment, agricultural robots generally have complex structures and control systems, which directly leads to the increase of the manufacturing costs. In addition, due seasonal characteristics of these robots, the low working time indirectly leads to the increase of the cost, which makes the current cost-value ratio of agricultural robots far from the market demands.
Lack of intelligence: In order to adapt to the complex agricultural production environment, agricultural robots must have a high level of intelligence. For example, in order to accurately locate crops, agricultural robots must have the functions of automatic path planning, navigation and obstacle avoidance. Although the research in recent years has made breakthroughs in machine vision, artificial intelligence and other aspects, the degree of intelligence of agricultural robots cannot meet the needs of the market.

\section{Conclusion}

Great achievements have been made in the development of agricultural robots. Some agricultural production activities can be completed independently by these robots. However, the overall popularization of agricultural robots still faces some challenges. With the development of automation technology, more new techniques will be applied in to this field. In the future, agricultural robots will be developed rapidly in the direction to highly intelligent, comprehensive functions and environmental protection. Agricultural robots will make great contributions to the development of agriculture.

\section{References}

1. Lee KW, Kim HR, Yoon CW, Kwon DS (2015) Designing a human-robot interaction framework for home service robot. IEEE International Workshop on 2005: 286-293.

2. Barbash GI, Glied SA (2010) New technology and health care costs-the case of robot-assisted surgery. New England Journal of Medicine 363: 701-704.

3. Wang W, Li R, Chen Y, Diekel Z, Jia Y (2018) Facilitating Human-Robot Collaborative Tasks by Teaching-Learning-Collaboration from Human Demonstrations. IEEE Transactions on Automation Science and Engineering 2018: 1-12.

4. Bechar A, Edan Y (2003) Human-robot collaboration for improved target recognition of agricultural robots. Industrial Robot: An International Journal 30: 432-436.

5. Monta M, Kondo N, Shibano Y (1995) Agricultural robot in grape production system. 1995 IEEE International Conference 1995: 25042509.

6. Sammons PJ, Furukawa T, Bulgin A (2005) Autonomous pesticide spraying robot for use in a greenhouse. Australian Conference on Robotics and Automation 2005: 1-9.

7. Kurata K (1994) Cultivation of grafted vegetables II. Development of grafting robots in Japan. HortScience 29: 240-244.

8. Van Henten E, Van Tuijl B, Hemming J, Kornet J, Bontsema J, et al. (2003) Field test of an autonomous cucumber picking robot. Biosystems engineering 86: 305-313.

9. Tanigaki K, Fujiura T, Akase A, Imagawa J (2008) Cherry-harvesting robot. Computers and electronics in agriculture 63: 65-72.

10. Pedersen SM, Fountas S, Have H, Blackmore B (2006) Agricultural robots-system analysis and economic feasibility. Precision agriculture 7: 295-308.

11. Bechar A, Vigneault C (2016) Agricultural robots for field operations: Concepts and components. Biosystems Engineering 149: 94-111.

12. Andreas DP, Jan A, De B (2018) Development of a Robot for Harvesting Strawberries. IFAC Papers OnLine 51(17): 14-19. 


\section{Robotics \& Automation Engineering Journal}

13. Zhang L (2012) Design and experimental study of automatic grafting vegetable grafting robot. Zhejiang Sci-Tech University 25(08): 2012.

14. Masayuki O, Shigeki A, Masahiro S (1997) Growth and Yield of Eggplants Grafted by a Newly Developed Robot 32(5): 848-849.

15. Tian S, Yang J, Xu D, Wang R (2016) Optimizing and Testing the Working Parameters of Cutting Device of Muskmelon Grafting Machine. Journal of Agricultural Engineering 32(22): 2016.

16. Liu C (2000) Research on automatic conveying system of vegetable grafting robot. China Agricultural University, China.

17. Liu P (2018) Design and research of apple picking robot. Xi'an University of technology, China.

18. Wu J (2018) Design and grasping characteristics of end effector of harvesting robot. Tianjin Agricultural University, China.

19. Lu Z (2015) Structural design and Simulation of quadruped weeding robot based on Virtual Prototyping Technology [D]. Kunming University of Technology, China.

20. Zhu G (2017) Design of intelligent spraying robot system. Jiamusi University, China

21. Hou T (2018) Design and Implementation of Tomato Picking Robot. Anhui Agricultural Science, China.

22. Stefan S, Roman D, Jakob G (2016) A New Robotic Spray Technology for Generative Manufacturing of Complex Concrete Structures Without Formwork, Procedia CIRP 43: 333-338.

23. Joseph D, Mano K, Chang M, Zhang Q (2017) Hand-Picking Dynamic Analysis for Undersense Robotic Apple Harvesting.

24. Guo Y (2017) Control method of milking robot manipulator. Agricultural science and technology and equipment 2017 (04): 18-20.

25. Yang C (2018) Structural Design of Milking Robot. Research on Agricultural Mechanization 40(04): 98-103.
26. Zhang J (2016) Application of diffuse reflection photoelectric switch in weeding robot. Sensor World 22(05): 19-22.

27. Song X, Wang J, Quan P (2016) Design and model implementation of an intelligent weeding robot. Innovation and application of science and technology 07: 16-17.

28. Yang S (2015) Research on the structure design of milking robot equipment. Harbin Engineering University, China.

29. Yang C (2018) Structural Design of Milking Robot. Research on Agricultural Mechanization 40(04): 98-103.

30. Wang W, Li R, Diekel ZM, Jia Y (2018) Robot action planning by online optimization in human-robot collaborative tasks. International Journal of Intelligent Robotics and Applications 2(2): 161-179.

31. Schraft RD, Meyer C, Parlitz C, Helms E (2005) Powermate-a safe and intuitive robot assistant for handling and assembly tasks. Proceedings of the 2005 IEEE International Conference on Robotics and Automation 2005: 4074-4079.

32. Wang W, Liu N, Li R, Chen Y, Jia Y (2018) HuCoM: A Model for Human Comfort Estimation in Personalized Human-Robot Collaboration. in ASME 2018 Dynamic Systems and Control Conference, pp. V002T23A006-V002T23A006.

33. Wang W, Li R, Diekel ZM, Jia Y (2018) Hands-free Maneuvers of Robotic Vehicles via Human Intentions Understanding using Wearable Sensing Journal of Robotics 4546094: 1-10.

34. Wang W, Li R, Chen Y, Jia Y (2018) Human Intention Prediction in Human-Robot Collaborative Tasks. Proc. 2018 ACM/IEEE International Conference on Human-Robot Interaction, 2018: 279-280.

35. Li M (2019) Application research of VR technology in picking robot simulation system. Agricultural Mechanization Research 41(05): 197201.

\section{Your next submission with Juniper Publishers} will reach you the below assets

- Quality Editorial service

- Swift Peer Review

- Reprints availability

- E-prints Service

- Manuscript Podcast for convenient understanding

- Global attainment for your research

- Manuscript accessibility in different formats

( Pdf, E-pub, Full Text, Audio)

- Unceasing customer service

Track the below URL for one-step submission https://juniperpublishers.com/online-submission.php 